\title{
Daily Flight Activity Rhythms of the Peach and Mediterranean Fruit Flies Using Sexual and Olfactory Attractants
}

\author{
M. H. BAYOUMY ${ }^{1^{*}}$ and M. M. EL-METWALLY ${ }^{2}$ \\ ${ }^{1}$ Faculty of Agriculture, Economic Entomology Department, Mansoura University, Mansoura 35516, Egypt \\ ${ }^{2}$ Plant Protection Research Institute, ARC, Dokki, Giza, Egypt
}

(Received: 16 March 2017; accepted: 19 April 2017)

\begin{abstract}
The periodicity of insect activity is affected by endogenous and exogenous factors, and these factor thresholds often limit its activity. The flight activity within $24 \mathrm{~h}$ circadian rhythm is often influenced by light, whereas the abundance is affected by temperature. This study aimed to hourly follow the flight activity of the peach (PFF) and Mediterranean (MFF) fruit flies, at guava orchard, using sexual and olfactory attractants. The flight of PFF males usually started before that of females, whereas that of MFF males was in the same time as females. As temperature rose above $30{ }^{\circ} \mathrm{C}$, the flight activity of males affected, but that of females not. Thus, flight activities of males were negatively, and females were positively, correlated with temperature. On the contrary, males were positively, and females were negatively, correlated with relative humidity. The sexual attractant attracted more PFF males than MFF, but the olfactory attractants attracted more PFF females than MFF. The highest male captures were between 7:00 am and 10:00 am, and females between 11:00 am and 5:00 pm, suggesting males fly actively during the morning to locate their mates, whereas females fly actively during the afternoon to locate their food and/or distribute their eggs. This also suggests that PFF and MFF are diurnal species. For management of both species, the spray treatments therefore should be taken during the time interval 7:00 am and 10:00 am for males (to disrupt mating) and 11:00 am and 5:00 pm for females (to disrupt feeding and oviposition).
\end{abstract}

Keywords: Bactrocera, Ceratitis, diurnal species, insect traps, management, temperature.

The fruit flies (Diptera: Tephritidae) are a group of serious species causing direct and indirect economic losses, all over the world. Infestations by fruit flies have been annually estimated at thousands of millions of US dollars of crop losses worldwide each year (Sarwar, 2006). The peach fruit fly (PFF), Bactrocera zonata (Saunders) is known as a highly destructive pest of tropical and subtropical fruits (Clarke et al., 2005). It attacks more than 50 host plant species (White and Elson-Harris, 1992). It is originated in South and South-East Asia and then spread to several regions of the world (Agarwal et al., 1999). PFF was officially recorded for the first time in guava orchards at Alexandria district, Egypt, in 1998. In 1999, higher capture rates were confirmed in traps (El-Minshawy et al., 1999). In 2000, it was recorded in North Sinai and numerous regions in Egypt (Hashem et al., 2001). In 2002, it has been confirmed in all areas of Egypt (Cayol et al.,

* Corresponding author; e-mail: mhmohamed@mans.edu.eg

0238-1249/\$20.00 (C) 2017 Akadémiai Kiadó, Budapest 
2002). The Mediterranean fruit fly (MFF), Ceratitis capitata (Wiedemann) is also one of the most serious pests attacking cultivated plants in the world. It attacks more than 300 different fruit species (Liquido et al., 1991). It is a species of Afrotropical origin which has adapted to the climatic conditions of the Mediterranean basin (Franco et al., 2006).

Both fruit fly species can be monitored by various types of traps baited with the male lure methyl eugenol (O-methyl eugenol) that attracts males at very low concentrations (Qureshi et al., 1992). Ammonia is considered to be the primary attractant for tephritids, and traps provided with the synthetic attractants of ammonia compounds have been highly successful in capturing these species. Numerous researchers evaluated the efficiency of ammonium compounds in attraction of PFF and MFF (Hanafy et al., 2001; Saafan, 2005; Moustafa and Ghanim, 2008; Kheder et al., 2011). Buminal is considered to be the main food attractant for catching fruit flies (Saafan, 2005). Ammonium compounds are more attractive to MFF and PFF than Buminal and Torula yeast (Hanafy et al., 2001; Amin and El-Metwally, 2011). The mass trapping technique by female- and male-attracted lures has to be involved in Integrated Pest Management program (IPM). Currently, the application of such lures in Mediterranean countries has substantially increased in control measurements (Navarro-Llopis et al., 2008).

The periodicity of insect activity is affected by endogenous and exogenous factors. Basically, exogenous factors are temperature, humidity, light and wind velocity, and these factor thresholds often limit the period of the activity (Willmer, 1982). The timing of flight activity in insects is often influenced by light intensity, whereas the capacity (numbers seen) is affected by temperature (Lewis and Taylor, 1964). Several activities requiring a circadian $(\sim 24 \mathrm{~h})$ regulation that became controlled by an endogenous molecular circadian clock, whose functioning has been recognized in several organisms (Bell-Pedersen et al., 2005). In insects, the clock controls the circadian rhythms of major aspects, like eclosion (Pittendrigh, 1954), oviposition (Howlader and Sharma, 2006), mating (Sakai and Ishida, 2001), and locomotor activity (Petersen et al., 1988). Presumably, insects have evolved means to respond to the daily light : dark cycle, as well as molecular clock mechanisms to expect daily rhythms of environmental factors that regulate their physiological and behavioral attributes in accordance (Dunlap et al., 2004). In general, these rhythms are known as "circadian rhythms". However, these rhythms are divided to: (1) "diel rhythms", i.e. the observed daily rhythms under light : dark conditions, which may or may not be endogenously driven by a molecular circadian clock; and (2) "true circadian rhythms", i.e. the observed rhythms under constant environmental conditions, which is endogenously regulated. Accordingly, a great diversity of biological processes is rhythmically organized, and potential is diminished if there is a difference between the environmental rhythm and the rhythm of the organism (Chiesa et al., 2015). The adaptive time-of-day regulated biology in some insects, for example, includes minimizing the risk of dry by being nocturnal because humidity is lower in the day than at night (Cloudsley-Thompson, 1960). Fruit fly species have been reported to have a distinct diurnal pattern of movement between their hosts and nearby non-host plants (e.g. Malavasi et al., 1983; Aluja et al., 1997). They were observed with a peak population inside the host fields during certain times of the day for oviposition, and then move out into the surrounding vegetation where feeding and resting take place. Information on movement of pest species is crucial for planning 
effective control programs (Bateman, 1972; Fletcher, 1989). Understanding the behavior and movement of insects may help in their management (Foster and Harris, 1997). For example, it is known that leaf hoppers in cotton and legume fields are hard to reach with insecticidal sprays because they reside on the underside of the lowest leaves of the plant. In the evening, however, they move to the tops of plants, which make them vulnerable to spraying (Van Emden and Service, 2004). This study therefore aimed to follow the daily flight activity rhythms of PFF and MFF.

\section{Materials and Methods}

\section{The experimental area and duration}

Two trials were conducted in guava (Psidium guajava L.) orchard located in the experimental farm of Mansoura University, Mansoura district $\left(31.03^{\circ} \mathrm{N}, 31.04^{\circ} \mathrm{E}\right)$ during the season of summer and autumn, 2016. The cultivated area was about 4.2 hectares (ten feddans). Five feddans were used for evaluating the flight activity of peach fruit fly (PFF), B. zonata and Mediterranean fruit fly (MFF), C. capitata using sexual attractants and the other five for olfactory attractants. The first trial was carried out within 3-successive days during summer season ( $30^{\text {th }}$ of August till $1^{\text {st }}$ of September, 2016), whereas the second one was during autumn season $\left(27^{\text {th }}\right.$ till $29^{\text {th }}$ of September, 2016).

\section{The tested compounds}

\section{A. Sexual attractant}

Two sexual attractants were applied: Trimedlure (TML) (98\% purity, manufactured in the USA), as specific attractant for MFF, and a commercial Methyl Eugenol (ME) (98\% purity, purchased YASHO Industry, India), as specific attractant for PFF. Cotton wicks ( $4 \mathrm{~cm}$ long $\times 1 \mathrm{~cm}$ diameter) were used as dispensers for each of TML and ME. The cotton wicks were individually injected, by medical syringe, with $3 \mathrm{ml}$ of the desired lure. Lures were placed in Jackson traps (Harris et al., 1971). Ten traps (as replicates) for each lure were hanged randomly in the shaded side of the fruit trees at a height of 1.5 meter where the distance between every two traps was 60 meter to avoid interaction between lures. Sticky cardboards inside the traps were examined every hour and number of attracted males was recorded per each trap, then cardboards were renewed.

\section{B. Olfactory attractants}

Two local olfactory attractants compounds from El-Naser Company for Drugs and Chemicals were evaluated. These compounds were ammonium acetate $\mathrm{CH}_{3} \mathrm{COONH}_{4}$ and diammonium phosphate $\left(\mathrm{NH}_{4}\right)_{2} \mathrm{HPO}_{4}$. The Nadel trap, that modified by Hanafy et al. (2001), was used in the trials. For each fruit fly species, ten traps (as replicates) baited with each attractant were distributed randomly where the distance between every two adjacent traps was 20 meters to avoid interaction between lures. All traps were hanged in a 
shaded place of the tree at a height of $1.5 \mathrm{~m}$ above the ground. Traps were examined every hour, captured flies were sexually inspected, and females were counted in laboratory.

\section{Weather records}

Hourly records of temperature and relative humidity were taken using the Thermo recorder TR-77Ui in the field. The average times for sunrise, sunset, and dusk during days of investigation at Mansoura district were retrieved from SunCalc (Agafonkin, 2014).

\section{Statistical analysis:}

The data of catches was analyzed by one-way ANOVA and means separated by Bonferroni test $(\alpha=0.05)$. Comparisons between trap catches of both fruit flies for each olfactory attractant and each daytime were performed using $t$-test $(\alpha=0.05)$. The Person product-moment correlation ( $r$ ) was performed to study the relation between the hourly flight catches of PFF as well as MFF either by sexual or olfactory attractants and each of temperature and relative humidity \% during summer and autumn seasons. All analyses were performed using Systat SigmaPlot 12 (Systat Software, San Jose, CA, 2011).

\section{Results}

\section{Daily rhythm of flight activity}

\section{Sexual attractants}

The daily flight activity of peach fruit fly (PFF) and Mediterranean fruit fly (MFF) was followed within 3-consecutive day investigations. The average times for sunrise, sunset, and dusk during days of summer season, 30/8, 31/8, 1/9/2016, were 05:31, 18:22, and 18:46; 05:31, 18:20 $\mathrm{h}$, and 18:45; 05:32, 18:19, and 18:44 h, respectively. Whereas, these averages were 05:49, 17:41, and 18:05 h; 05:50, 17:39, and 18:04 h; and 05:50, 17:38, and 18:02 h during investigation days, 1/10, 2/10,3/10/2016, of autumn season, respectively. Figures 1 and 2 show the average number of adult males of both fruit fly species trapped each hour on sex attractant traps. The flight activity of PFF males started after lights-on (6:00 am - 7:00 am) in summer season, whereas it delayed one more hour during autumn season (7:00 am - 8:00 am) and continued for the entire 24-hour. Male flight of PFF started in the morning after sunrise between 6:00 am - 7:00 am with minor peaks between 9:00 am - 10:00 am, and 2:00 pm - 3:00 pm during summer season. In autumn season, male flight of PFF peaked on 7:00 am - 8:00 am, 10:00 am - 11:00 am and 2:00 pm $-3: 00 \mathrm{pm}$. In respect to MFF, male flight was relatively low during summer season with a slight peaks began between 8:00 am - 9:00 pm and 5:00 pm - 6:00 pm. This low flight movement continued for the whole 12-hour of daylight. In autumn season, two main peaks for males were recorded within the period of 8:00 am - 9:00 am and 3:00 am $-4: 00 \mathrm{pm}$. On lights-off till sunrise (7:00 pm - 6:00 am), male flight was stopped. 


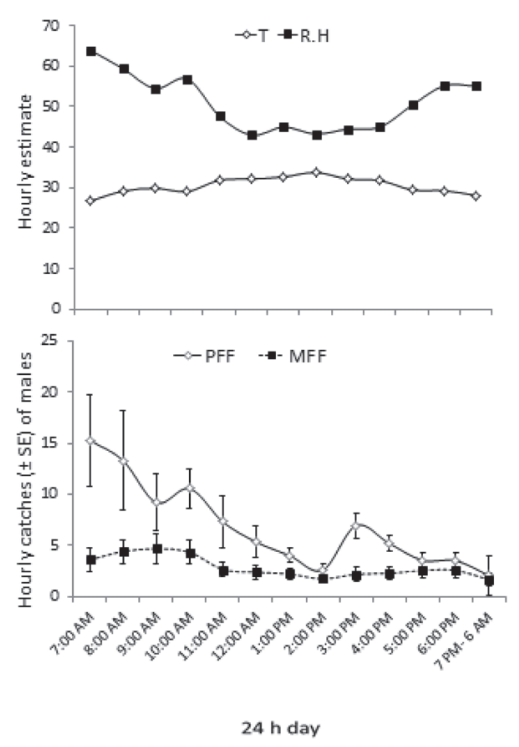

Fig. 1. Daily rhythm of flight activity for adult males of Bactrocera zonata (PFF) and Ceratitis capitata (MFF) caught in sex attractant traps in corresponding to hourly fluctuates of temperature and relative humidity during summer season in a guava orchard located at Mansoura University farm
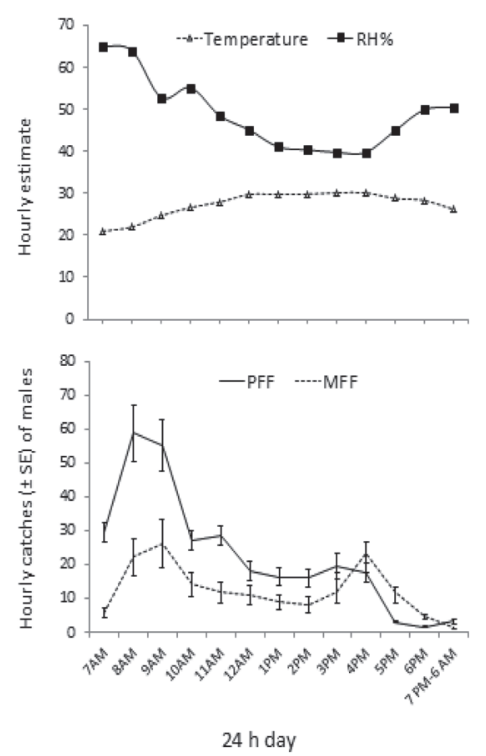

Fig. 2. Daily rhythm of flight activity for adult males of Bactrocera zonata (PFF) and Ceratitis capitata (MFF) caught in sex attractant traps in corresponding to hourly fluctuates of temperature and relative humidity during autumn season in a guava orchard located at Mansoura University

farm

Males of both species flew sedentary after lights-off during the rest of the dark period. The results showed that MFF exhibited only diurnal movements in the experimental orchard, whereas PFF males exhibited diurnal and evening movements, despite it was lower during dusk periods. Flight appeared to be reduced in both species at temperatures above $30^{\circ} \mathrm{C}$ and most common between $20-30{ }^{\circ} \mathrm{C}$ (Figs 1,2 ). The number of PPF males caught in sex attractant traps during daylight hours varied inversely with temperature in both seasons of study, but varied exponentially with relative humidity. Whereas, the number of MFF males did not vary significantly with both prevailing weather factors, except with RH\% during summer season (Table 1). Over 3-successive day of investigations, traps caught higher numbers of PFF males than MFF during the different periods of the day, regardless the season of study. There was no significant difference between the cumulative number of PFF and MFF males caught by sexual attractants during nighttime $(6: 00 \mathrm{pm}$ $-6: 00 \mathrm{am})(t=1.08, \mathrm{df}=4, P=0.34$, Fig. 3$)$, whereas there were significant differences during day morning $(7: 00 \mathrm{~h}-10: 00 \mathrm{~h})$ and day afternoon $(11: 00 \mathrm{am}-5: 00 \mathrm{pm})$, (day morning: $t=2.69, \mathrm{df}=6, P=0.03$; day afternoon: $t=2.31, \mathrm{df}=10, P=0.04$, with a greater flight activity of adult males of both fruit fly species during diurnal periods (Fig. 3). 


\section{Olfactory attractants}

\section{Ammonium acetate}

Figures 4 and 5 show the average number of adult females of both fruit fly species trapped each hour in traps baited with ammonium acetate attractant compound. Females of both species began flight activity after lights-on (7:00 am - 9:00 am) in both seasons, and continued for the entire 12-hour of daylight. Male flight of PFF started in the morning after sunrise between 7:00 am - 8:00 am with major peaks between 11:00 am - 12:00 am and 3:00 pm - 4:00 pm during summer season, whereas it was during 8:00 am - 9:00 am and 3:00 pm - 4:00 pm during autumn season. In respect to MFF, male flight began between 8:00 am - 9:00 am and 9:00 am - 10:00 am during summer and autumn season, respectively, and also continued for the entire 12-hour of daylight. In summer season, male flight of MFF peaked during 1:00 pm - 2:00 pm and 3:00 pm - 4:00 pm, but in autumn season, peaked during 8:00 am - 9:00 am and 3:00 pm - 4:00 pm. The results showed that PFF and MFF females exhibited only diurnal movements in the experimental orchard. Female flight appeared to be reduced in both species at relative humidity above $50 \%$ and most common below 50\% (Figs 4, 5).

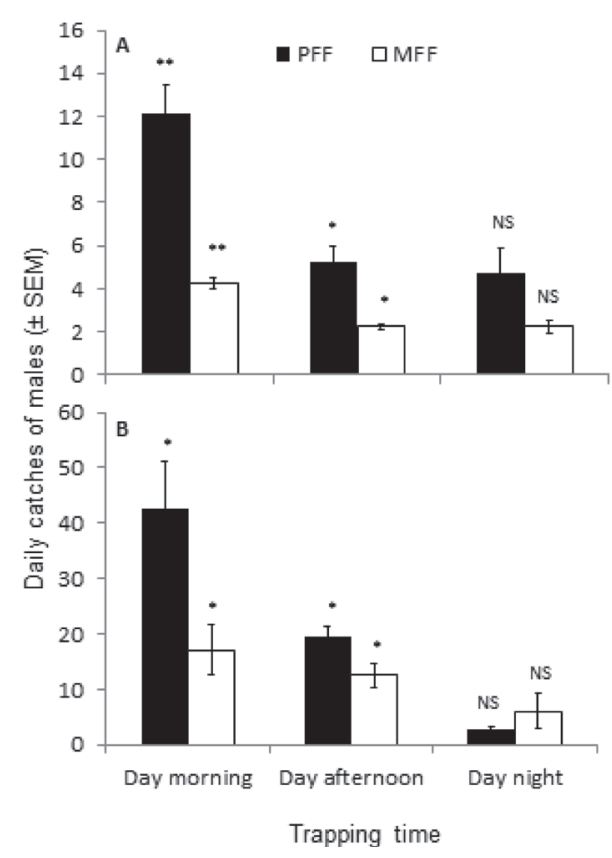

Fig. 3. Comparison between trap catches during different day times of Bactrocera zonata (PFF) and Ceratitis capitata (MFF) males using sexual attractants during summer (A) and autumn (B) seasons in a guava orchard located at Mansoura University farm. Pairs compared using $t$-test $(\alpha=0.05)$

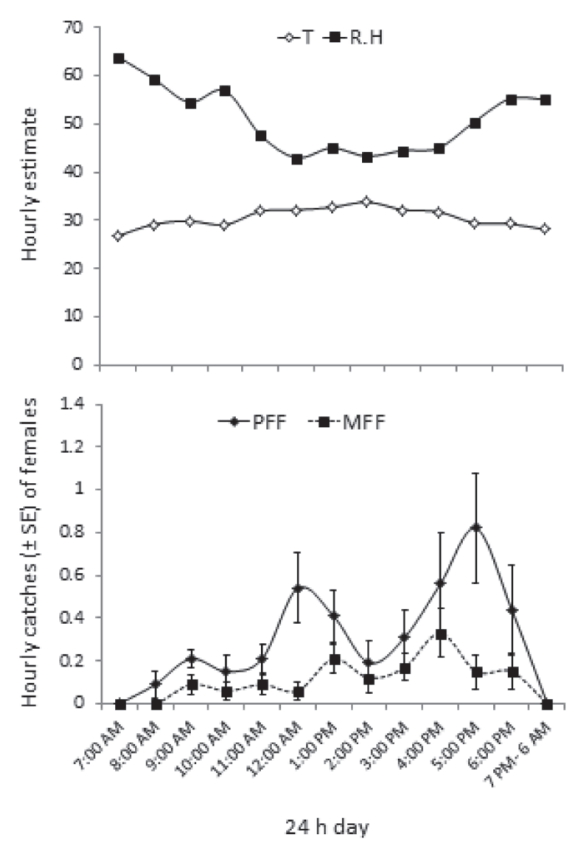

Fig. 4. Daily rhythm of flight activity for adult females of Bactrocera zonata (PFF) and Ceratitis capitata (MFF) responded to ammonium acetate olfactory attractants in corresponding to hourly fluctuates of temperature and relative humidity during summer season in a guava orchard located at Mansoura University farm 
Table 1

The Person product-moment correlation (r) and probability levels (P) between the hourly flight numbers of adult Bactrocera zonata (PFF) and Ceratitis capitata (MFF) caught either by sexual or olfactory attractant compounds and hourly records of temperature and relative humidity \% during summer and autumn seasons in a guava orchard located at University farm

\begin{tabular}{|c|c|c|c|c|c|c|c|c|c|}
\hline \multirow[t]{4}{*}{ Compounds } & & \multicolumn{8}{|c|}{ Weather } \\
\hline & & \multicolumn{4}{|c|}{ Temperature } & \multicolumn{4}{|c|}{ Relative humidity $\%$} \\
\hline & & \multicolumn{2}{|c|}{ Summer } & \multicolumn{2}{|c|}{ Autumn } & \multicolumn{2}{|c|}{ Summer } & \multicolumn{2}{|c|}{ Autumn } \\
\hline & & $r$ & $P$ & $R$ & $P$ & $r$ & $P$ & $r$ & $P$ \\
\hline \multirow[t]{2}{*}{ Sexual } & PFF Ơ' & -0.66 & 0.01 & -0.63 & 0.02 & +0.78 & 0.002 & +0.56 & 0.04 \\
\hline & MFF ƠO' & -0.49 & 0.09 & -0.14 & 0.66 & +0.66 & 0.01 & +0.07 & 0.82 \\
\hline \multirow{2}{*}{$\begin{array}{l}\text { Ammonium } \\
\text { acetate }\end{array}$} & PFF Q̊ & +0.37 & 0.22 & +0.51 & 0.08 & -0.56 & 0.05 & -0.59 & 0.03 \\
\hline & MFF OQ & +0.57 & 0.04 & +0.47 & 0.11 & -0.63 & 0.02 & -0.49 & 0.09 \\
\hline \multirow{2}{*}{$\begin{array}{l}\text { Diammonium } \\
\text { phosphate }\end{array}$} & PFF Qॄ⿻ & +0.41 & 0.17 & +0.61 & 0.03 & -0.54 & 0.06 & -0.70 & 0.008 \\
\hline & MFF OQ & +0.28 & 0.36 & +0.58 & 0.04 & -0.48 & 0.10 & -0.57 & 0.04 \\
\hline
\end{tabular}

The number of females of both species caught in traps provided with ammonium acetate lures did not vary with temperature of both seasons of study, except for MFF during summer season. In contrast, number of females for both species varied inversely $(P<0.05)$ with relative humidity, except for MFF during autumn (Table 1).

\section{Diammonium phosphate}

Figures 6 and 7 show the average number of adult females of both fruit fly species trapped each hour in traps baited with diammonium phosphate lures. The flight activity of PFF female initiated after lights-on (7:00 am - 8:00 am) in summer season, whereas it began one hour later during autumn season (8:00 am - 9:00 am) and continued for the entire 12-hour of daylight. In respect to MFF females, it began after lights-on (8:00 am 9:00 am) in summer season and 7:00 am - 8:00 am during autumn and also continued for the entire 12-hour of daylight. In summer season, females of both species had one peak of flight activity at afternoon (3:00 pm - 4:00 pm), despite the low population of MFF females captured. In autumn season, females had two distinct peaks of flight activity, but in different times. Female flight of PFF peaked on 8:00 am - 9:00 am and 1:00 pm $-2: 00 \mathrm{pm}$, whereas MFF on 7:00 am - 8:00 am and 3:00 pm - 4:00 pm. Traps captured higher numbers of MFF females in autumn than summer season. On lights-off till sunrise (7:00 pm - 6:00 am), female flight was reduced. Thus, the results showed that PFF and MFF females exhibited only diurnal movements in the experimental orchard. Female flight appeared to be reduced in both species at relative humidity above $50 \%$ and most common below $50 \%$ (Figs 6, 7).

The number of females of both species caught in traps baited with ammonium acetate lures hours differed according to the weather factors owned to the season. The females of PFF did not vary with variation in temperature and relative humidity during summer season, whereas female numbers of both species increased significantly with increasing of temperature and decreasing of relative humidity during autumn season (Table 1). 

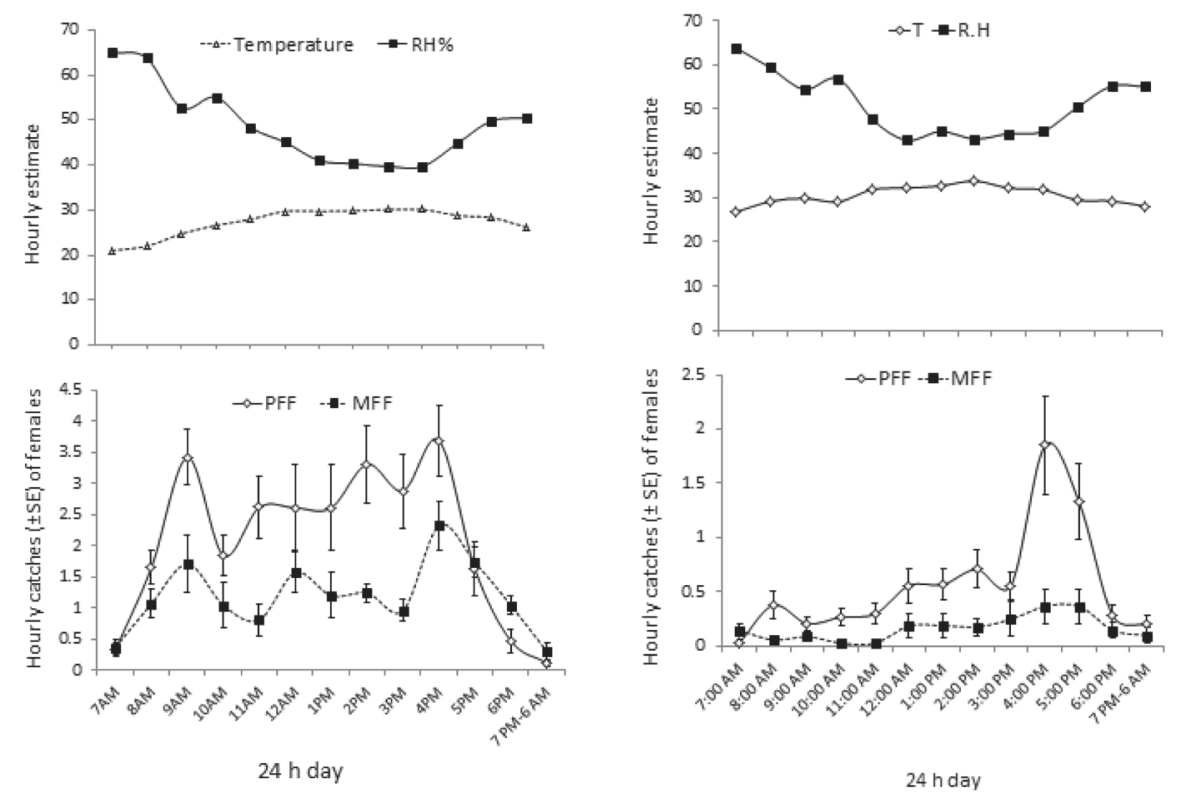

Fig. 5. Daily rhythm of flight activity for adult females of Bactrocera zonata (PFF) and Ceratitis capitata (MFF) responded to ammonium acetate olfactory attractants in corresponding to hourly fluctuates of temperature and relative humidity during autumn season in a guava orchard located at Mansoura University farm

Fig. 6. Daily rhythm of flight activity for adult females of Bactrocera zonata (PFF) and Ceratitis capitata (MFF) responded to diammonium phosphate attractants in corresponding to hourly fluctuates of temperature and relative humidity during summer season in a guava orchard located at Mansoura University farm

\section{Efficiency of sexual and olfactory attractants}

\section{Sexual attractants}

It was noticed in the location of experiment that the average numbers of PFF males caught by sexual attractants were significantly higher than those of MFF during summer $(t=2.13, \mathrm{df}=24, P=0.04)$ and autumn seasons $(t=3.87, \mathrm{df}=24, P=0.03)$. Male catches of both species in deployed traps were higher during autumn than summer season. During the $24 \mathrm{~h}$ cycle, the trap catches of PFF were almost 2-fold higher than MFF, regardless the season of study (Fig. 8).

\section{Olfactory attractants}

During the 24-h cycle, the average numbers of PFF and MFF females attracted in traps baited with ammonium acetate (AA) and diammonium phosphate (DP) compounds were significantly differed during summer season (AA: $t=2.08, \mathrm{df}=258, P=0.04$; DP: $t=4.24$, df $=258, P<0.001$; Fig. 9). Comparison between both olfactory compounds revealed that PFF females were more attracted to AA compared than DP $(t=3.09, \mathrm{df}=258$, $P=0.002)$, whereas catches of MFF females did not vary $(t=1.73, \mathrm{df}=258, P=0.08)$ 


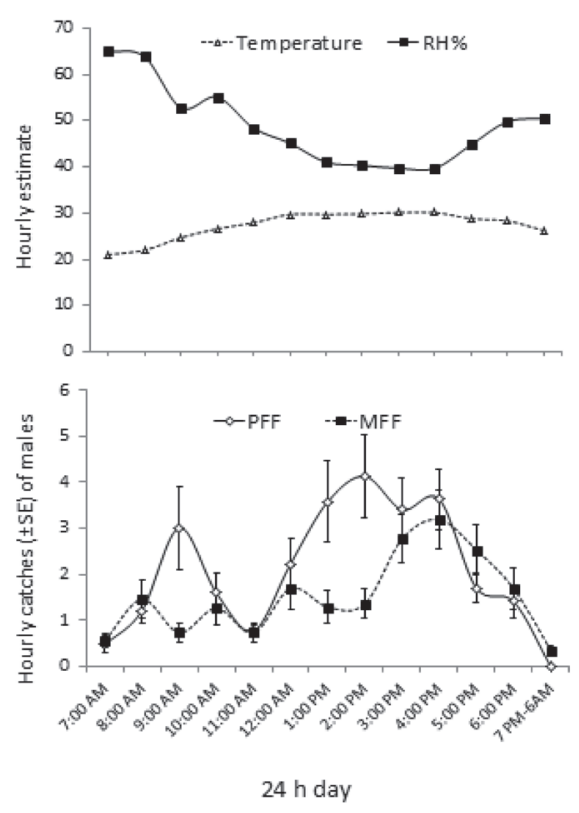

Fig. 7. Daily rhythm of flight activity for adult females of Bactrocera zonata (PFF) and Ceratitis capitata $(\mathrm{MFF})$ responded to diammonium phosphate attractants in corresponding to hourly fluctuates of temperature and relative humidity during autumn season in a guava orchard located at Mansoura University farm

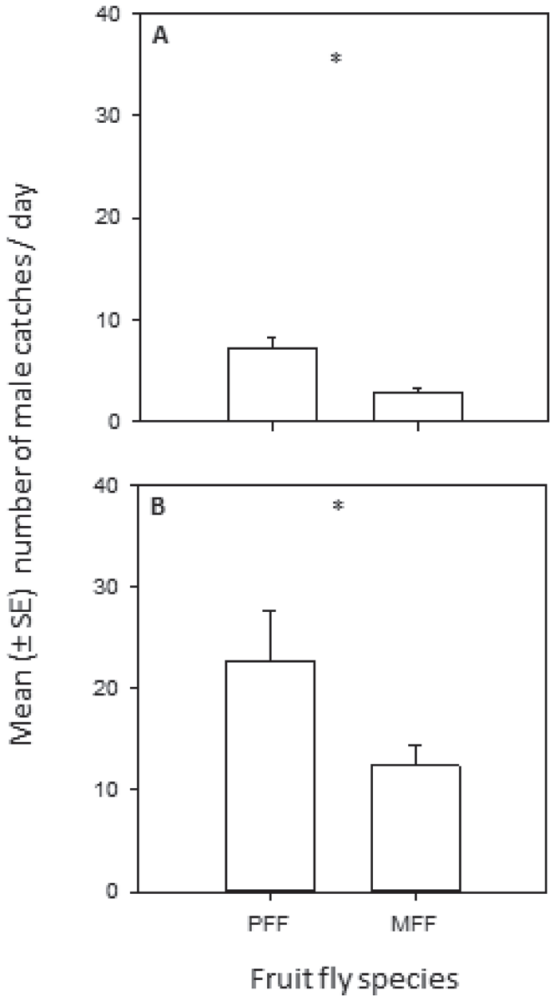

Fig. 8. Comparison between average daily catches ( \pm SEM) of Bactrocera zonata (PFF) and Ceratitis capitata (MFF) males using sexual attractant during summer (A) and autumn (B) seasons in a guava orchard located at Mansoura University farm. Asterisks compare between means using $t$-test $(\alpha=0.05)$

(Fig. 9). In autumn season, the average numbers of attracted PFF and MFF females differed significantly in traps baited with ammonium acetate (AA), but did not in traps with diammonium phosphate (DP) compounds (AA: $t=4.51, \mathrm{df}=258, P<0.001$; DP: $t=1.81$, $\mathrm{df}=258, P=0.08$; Fig. 10). Comparison between both olfactory compounds revealed that there was no difference in PFF and MFF female catches between the two olfactory compounds (PFF: $t=0.88, \mathrm{df}=258, P=0.39$; MFF: $t=1.18, \mathrm{df}=258, P=0.07$ ) (Fig. 10).

\section{Discussion}

The highest numbers of PFF males caught by Jackson trap were during August, September and October (Mohamed, 2002; Draz et al., 2016). The MFF adults had two 


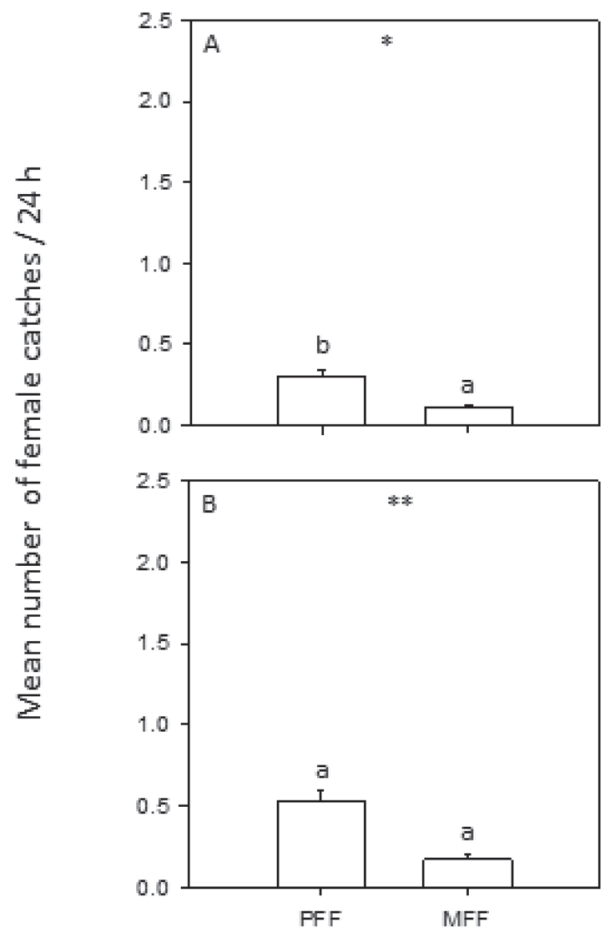

Fruit fly species

Fig. 9. Comparison between average daily catches ( \pm SE) of Bactrocera zonata (PFF) and Ceratitis capitata (MFF) females using ammonium acetate (A) and diammonium phosphate (B) during summer season in a guava orchard located at Mansoura University farm. Asterisks compare horizontally between both columns in the same partitioned figure, whereas small letters compare vertically between columns in both partitions of the figure ( $t$-test, $\alpha=0.05$ )

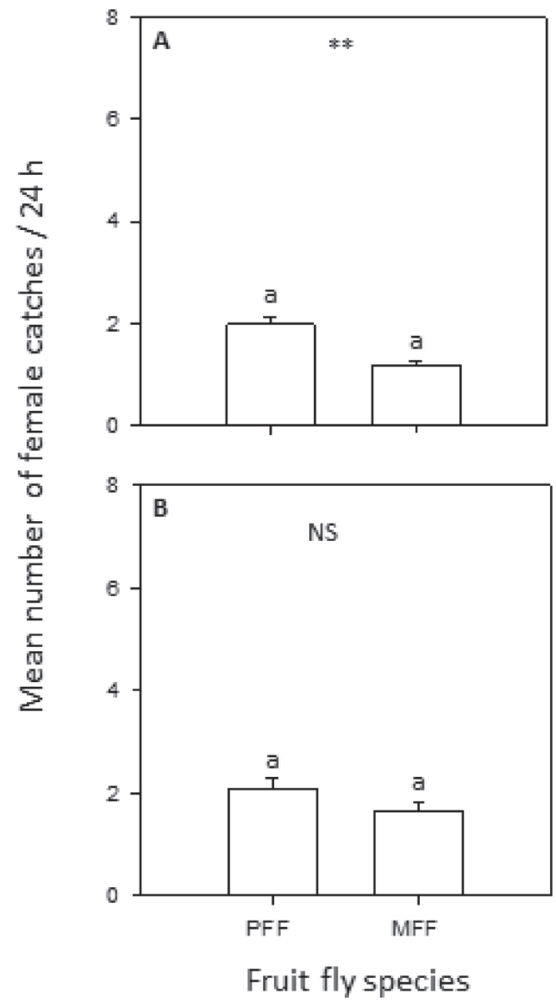

Fig. 10. Comparison between average daily catches ( \pm SE) of Bactrocera zonata (PFF) and

Ceratitis capitata (MFF) females using ammonium acetate (A) and diammonium phosphate (B) during autumn season in a guava orchard located at Mansoura University farm. Asterisks compare horizontally between both columns in the same partitioned figure, whereas small letters compare vertically between columns in both partitions of the figure ( $t$-test, $\alpha=0.05$ )

peaks: one in summer and the second one in autumn season (e.g., Katsoyannos et al., 1998; Martínez-Ferrer et al., 2010). The appropriate height for hanging traps within the tree for catching fruit flies was $1.5 \mathrm{~m}$ (El-Gendy, 2012), and the most preferred fruits to PFF were pear followed by guava (Shehata et al., 2008). Jones et al. (1983) mentioned that the best time to monitor males of fruit flies in the Mediterranean area is between May and December when mating activity occurs. For both fruit fly species, the effectiveness of the technique highly depends on the type of trap and attractant. Trimedlure is a sex-specific attractant that widely recommended in detection and monitoring programs (Beroza et al., 1961). It is a parapheromone, and no disruption consequences have been performed 
although it has been extensively implemented as male attractants. According to these previous literatures and our conditions, we designed the current study.

Temperature is a very important factor that regulates different biological processes in fruit flies (Bateman, 1972). Regardless the season of study, the probability level, and the fruit fly species; the flight activity, of both sexes of both species, in response to temperature and relative humidity was in opposite directions. The flight activity of males was negatively correlated with temperature, whereas females positively correlated with temperature. In contrast, males of both species were positively correlated with relative humidity, whereas females were negatively correlated with relative humidity. This could be proved by the highest captures of PFF and MFF during the period of 7:00 am - 10:00 am, whereas those of females during the period of 11:00 am - 5:00 pm. A significant positive correlation between PFF populations and temperatures, and a significant negative correlation with R.H.\% was obtained in Sohag and Assiut Governorates (Ali et al., 2011), in India (Nripendra and Hirak, 2010; Sundar et al., 2015). However, Sanjeev et al. (2008) in India mentioned that humidity had a positive effect on the population of Bactrocera dorsalis (Hendel) and B. zonata, and Hasyim et al. (2008) found that the catches in cue-lure baited traps were correlated positively with humidity. Differences in response to temperature between both sexes are probably because the different heat requirements for each sex. Furthermore, this could be explained by the low flight activity of males between 11:00 am - 2:00 pm where temperature was above $30^{\circ} \mathrm{C}$, whereas the activity of females did not reduce at the same period.

The periodicity of reproductive and flight in most insects are usually affected by low temperature that could switch the timing of the circadian rhythm. Low temperatures could advance nighttime into early evening or even late afternoon, while morning mating could be delayed to midday (Jackson and Resh, 1991). This flexibility is critical for some insect species because it allows them to overcome on unsuitable low temperatures that would require intensive amounts of metabolic energy for mating flight, or even completely inhibit mating flight (Cardé et al., 1975), or high temperatures that would increase the rate of respiration, and reduce the investment in mating. Our data suggested that male flight activity of both species was begun after dawn and that activity reduced between 11:00 am - 2:00 $\mathrm{pm}$. There was a smaller peak of activity near sunset $(2: 00 \mathrm{pm}-4: 00 \mathrm{pm})$. Similar results were reported on the silverleaf whitefly [Bemisia tabaci (Gennadius)], which showed the longest flight duration between 06:00 am and 10:00 am (Blackmer and Byrne, 1993), and the congeneric spiraling whitefly (Aleurodicus disperses Russell) adults were most active in flight around dawn and dusk (Han et al., 2009). The lower flight activity of males during midday probably because the solar radiation and temperatures recorded at field were higher than $30{ }^{\circ} \mathrm{C}$. Variations in observed periodicities are certainly due either to various activities being noted, or to weather factors. Very hot days or areas seem to make the flies to rest during the hottest times of the day (Nielsen, 1966), or to switch to the cooler areas (Maier and Waldbauer, 1979). Midday rests made a bimodal activity pattern; Zimina (1957) noted that visiting the flowers in late afternoon for feeding was habit of hoverflies. Changes in activity and spatial aggregation are certainly very important.

The flight of PFF males usually started before that of females, whereas that of MFF males started in the same time of females. As reproduction is, in the end, the most signif- 
icant targeted activity of the adult stage, the periodicity of male and female flight activity should simplify male location and may therefore vary between the sexes. For instance, males that remain in one place during the period of mate attraction should have not greater chance of perceiving a pheromone plume and locating pheromone-releasing females compared with males that fly actively during this period. Inversely, females that are stable during the period of mate attraction more likely intercepting pheromone trails that are simply for males to follow than those intercepting by actively flying females. Males of PFF conform to this pattern in that they fly actively during the first hours, prior to females, of the mate attraction period (i.e. immediately after lights-off). This pattern, however, is not of endogenous origin and may have been a sudden reaction due to the abrupt change in light intensity. Whereas both sexes of MFF did not conform this pattern in that both fly concurrently. The highest captures of males during the time interval 7:00 am and 10:00 am, and females within the period 11:00 am and 5:00 pm, suggesting males fly actively during the morning to locate their mates, whereas females, probably those mated, fly actively from late morning until the end of the afternoon due to their intensively need to food and/or distributing their eggs. Females Anastrepha fraterculus (Wiedemann) (Diptera: Tephritidae) will need more protein after first mating to keep subsequent ovarian cycles which may last up to seven hours, and males need more carbohydrate to compensate the energy spent mainly in calling activity (Browne, 1993).

Because of the importance of light in behavior, males that were trapped during the daytime suggesting that the PFF and MFF are diurnal species. Very few males were attracted by sexual attractant at night, indicating a failure in perceiving volatiles cues, or a lack of flight movement and/or a disability of locating the trap at night. However, the lower accumulated male catches in traps at dusk ( $7 \mathrm{pm}-6 \mathrm{am})$ may result from crepuscular light appear before dusk and after dawn during the days of investigation. These findings are similar to those obtained by olfactory attractants. Our results therefore suggest that PFF and MFF are positively phototactic and their behavior is controlled by light. Due to the importance of light in movement, both species are certainly a diurnal insect species with low activity at night since the perception of visual cues is diminished.

It is clear from matching the two curves of flight activity for each fly sex within each season that the first flight of PFF males was one hour earlier than females, whereas that of females of both species started to fly, at day morning, almost at the same time. Furthermore, males of PFF started to fly one hour earlier than those of MFF. This suggests that early hours after sunrise seem to be the preferred time for both sexes to mate. As known for most of important tephritid species examined thus far, sexual signaling in Bactrocera and Ceratitis usually encompasses the production and emission of sex pheromone by males (a behavior termed "calling") while resting on vegetation for detecting and subsequent mate searching by receptive females (e.g. Féron, 1962; Briceňo et al., 2005). Information regarding diel rhythms of male-male and female-female aggressions in Tephritid species is not sufficient. Most of the observations on aggressive behavior have been derived from mating and courtship studies. Little information has been available on the time of aggressions within a day (Benelli, 2014). However, the medfly, MFF, males aggregate beneath the neighboring leaves on a fruit and release a pheromone to attract females (a system termed "a lekking-mating") (Whittier et al., 1992). Consequently, the males ag- 
gregate in leks, in the early morning and afternoon, depending on weather factors (Féron, 1962). The differences in male emergence of PFF and MFF at day morning, but not in female emergence probably suggest also an absent of interspecific interference.

Regardless the sex of fruit fly species and the attractant, trap catches particularly of PFF were significantly higher in autumn season than summer season. This could be explained from correlation tests, in which both species were negatively responded $(P<0.05)$ to summer temperature and positively $(P<0.05)$ to autumn temperature. Thus, autumn seems to be a more suitable season for fruit fly infestations. Interspecific competition among female catches did differ significantly by both olfactory attractants in both seasons of study. Each attractant significantly caught higher numbers of PFF females than MFF in both seasons. That means that PFF females seem to be stronger than MFF in detection of the released ammonia from long distance. In contrast, female catches of each species did not differ significantly by each olfactory attractant in both seasons of study. Only, diammonium acetate was more effective in attractive PFF females in summer than autumn season. In Egypt, Moustafa and Ghanim (2008) found that the highest numbers of $C$. capitata and $B$. zonata were attracted by ammonium acetate regardless the concentration tested in comparison with other ammonium compounds. However, our results partially inconsistent with those of Thomas et al. (2008), who found that ammonium acetate that releasing acetic acid alongside with the ammonia was better for attracting Mexican fruit fly Anastrepha ludens (Loew) than ammonium bicarbonate, which releases carbon dioxide along with the ammonia. Such differences of response could be interpreted when considering the effect of weather factors, fruiting period and variations in response among insect species. Implementation of attractants for control is an objective of using the attractants not only for detecting and monitoring, but also for controlling of fruit flies (Navarro-Llopis et al., 2008). Therefore, the two examined olfactory compounds, particularly the local ammonium acetate, should be used in monitoring populations of fruit flies, flight activity, and in mass trapping as a part of IPM programs.

The flight activity of both fruit fly species examined here is temporally short and coordinated, and the periodicity of flight (and probably mating) activities was controlled by the biological clock. This indicates that the partitioned diel activities have been evolutionarily useful for both species, perhaps because their fitness may be affected by diel variations in environmental conditions (e.g. temperature, light, humidity, predation risk, interspecific interference) and by the limited metabolic resources and shorted life-spans of adults (Jackson and Resh, 1989). These results suggest that males of fruit flies are more active during the morning, whereas females during the afternoon. For management of both species, the spray treatments therefore should be taken during the time interval 7:00 $\mathrm{h}$ and 10:00 $\mathrm{h}$ for males (to disrupt mating) and 11:00 am and 5:00 pm for females (to disrupt feeding and oviposition). However, further studies should be taken in account to validate these outcomes. A preliminary study of diurnal activity trials suggested the best time of day to control Bactrocera cucurbitae (Coquillett) and B. dorsalis may be during the first hours in morning. Nevertheless, if the regulatory factor for their activity is temperature, late afternoon would be suitable as well (Guamán, 2009). The findings from the current study may help to improve the management of these fruit flies by identifying the best time for monitoring, trapping, and sampling, and other management strategies. 


\section{Acknowledgements}

The authors thank Prof. Dr. Talal S. EL-abbassi, Director of National Program to Exterminate Fruit Flies in Egypt (Agricultural Research Center, Ministry of Agriculture), for his review of the experimental design and two anonymous referees for suggestions and comments that greatly improved the manuscript.

\section{Literature}

Agafonkin, V. (2014): SunCalc. http://www.suncalc.net/.

Agarwal, M. L., Pramod, K. and Kumer, P. (1999): Effect of weather parameters on population dynamics of peach fruit fly, Bactrocera zonata (Saunders). Entomology 24, 81-84.

Ali, H., Ahmad, S., Hassan, G., Amin, A., Hussain, Z. and Naeem, M. (2011): Bioefficacy of different plant extracts against melon fruit fly in bitter gourd. Pakistan J. Weed Science Research 17, 143-149.

Aluja, M., Jiménez, A., Piñero, J., Camino, M., Aldana, L., Valdés, M. E., Castrejón, V., Jácome, I., Dávila, A. and Figueroa, R. (1997): Daily activity patterns and within-field distribution of papaya fruit flies (Diptera: Tephritidae) in Morelos and Veracruz, Mexico. Ann. Entomol. Soc. Am. 90, 505-520.

Amin, A. A. and El-Metwally, M. M. (2011): Field evaluation of some attractants for Mediterranean and peach fruit flies in Egypt. Assiut J. Agric. Sci. 42, 165-178.

Bateman, M. A. (1972): The ecology of fruit flies. Annu. Rev. Entomol. 17, 493-518.

Bell-Pedersen, D., Cassone, V. M., Earnest, D. J., Golden, S. S., Hardin, P. E., Thomas, T. L. and Zoran, M. J. (2005): Circadian rhythms from multiple oscillators: lessons from diverse organisms. Nat. Rev. Genet. 6, $544-556$.

Benelli, G. (2014): Aggressive behavior and territoriality in the olive fruit fly, Bactrocera oleae (Rossi) (Diptera: Tephritidae): Role of residence and time of day. J. Insect Behav. 27, 145-161.

Beroza, M., Green, N., Gertler, S. I., Steiner, L. F. and Miyashita, D. H. (1961): Insect attractants: new attractants for the Mediterranean fruit fly. J. Agric. Food Chem. 9, 361-365.

Blackmer, J. L. and Byrne, D. N. (1993): Environmental and physiological factors influencing phototactic flight of Bemisia tabaci. Physiological Entomol. 18, 336-342.

Briceňo, R. D., Eberhard, W. G. and Quilici, S. (2005): Comparative allometry and sexual behavior of four fruit fly species in the tribe Ceratitidini (Diptera: Tephritidae). J. Kansas Entomol. Soc. 1, 20-33.

Browne, L. B. (1993): Physiologically induced changes in resource-oriented behaviour. Annu. Rev. Entomol. $38,1-25$.

Cardé, R. T., Comeau, A., Baker, T. C. and Roelofs, W. L. (1975): Moth mating periodicity: Temperature regulates the circadian gate. Experientia 31, 46-48.

Cayol, J. P., Rossler, Y., Weiss, M., Bahdousheh, M., Omari, M., Hamalawi, M. and Almughayyar, A. (2002): Fruit fly control and monitoring in the Near East: Shared concern in a regional trans boundary. Proc. of the 6th International Symposium on fruit flies of economic importance. Stellenbosch, South Africa, pp. $155-171$.

Chiesa, J. J., Duhart, J. M., Casiraghi, L. P., Paladino, N., Bussi, I. L. and Golombek, D. A. (2015): Effects of circadian disruption on physiology and pathology: From bench to clinic (and back). In: R. Aguilar-Roblero, M. Díaz-Muñoz and M. L. Fanjul-Moles (eds): Mechanisms of Circadian Systems in Animals and Their Clinical Relevance. Springer, Gewerbestrasse, Switzerland, pp. 289-320.

Clarke, A. R., Armstrong, K. F., Carmichael, A. E., Milne, J. R., Raghu, S., Roderick, G. K. and Yeates, D. K. (2005): Invasive phytophagous pests arising through a recent tropical evolutionary radiation: The Bactrocera dorsalis complex of fruit flies. Annu. Rev. Entomol. 50, 293-319.

Cloudsley-Thompson, J. L. (1960): Adaptive functions of circadian rhythms. Cold Spring Harb. Symp. Quant. Biol. 25, 345-355.

Draz, R. M., Tabikha, M. A., El-Aw, I. R. and Darwish, E. F. H. (2016): Population activity of peach fruit fly Bactrocera zonata (Saunders) (Diptera: Tephiritidae) at fruits orchards in Kafer El-Sheikh Governorate Egypt. Arthropods 5, 28-43. 
Dunlap, J. C., Loros, J. J. and Decoursey, P. J. (2004): Chronobiology: Biological Timekeeping. Sinauer Associates, Sunderland, MA, USA.

El-Gendy, I. R. (2012): Studies on peach fruit fly, Bactrocera zonata (Saunders) at El-Beheira Governorate. MSc Thesis, Fac. of Agric., Damanhour branch. Alexandria University, Egypt.

El-Minshawy, A. M., El-Eryan, M. A. and Awad, A. I. (1999): Biological and morphological studies on the guava fruit fly, Bactrocera zonata (Saunders) (Diptera: Tephritidae) found recently in Egypt. $8^{\text {th }}$ Nat. Conf. Pests and Dis. of Veg. and Fruits in Ismailia, Egypt, pp. 71-82.

Féron M. (1962): L'instinct de réproduction chez la mouche Mediterraneenne des fruits Ceratitis capitata Wied. (Dipt. Trypetidae). Comportement sexuel - comportement de ponte. Rev. Path. Veg. Entomol. Agr. France 41, 1-129.

Fletcher, B. S. (1989): Ecology; movements of tephritid fruit flies. In: A. S. Robinson and G. Hooper (eds): World Crop Pests 3(B). Fruit Flies, their Biology, Natural Enemies and Control. Elsevier, Amsterdam, Netherlands, pp. 209-219.

Foster, S. P. and Harris, M. O. (1997): Behavioral manipulation methods for insect pest-management. Annu. Rev. Entomol. 42, 123-146.

Franco, J. C., Garcia-Marí, F., Ramos, A. P. and Besri, M. (2006): Survey on the situation of citrus pest management in Mediterranean countries. IOBC/WPRS Bull 29, 335-345.

Guamán, V. (2009): Monitoring and pest control of fruit flies in Thailand: New knowledge for integrated pest management. Swedish University of Agricultural Sciences, Faculty of Natural Resources and Agricultural Sciences, Department of Ecology, SLU-10293, Uppsala, Independent project, 37 p.

Han, D.-Y., Liu, K., Zhang, F.-P., Huang, W.-R., Zhang, J.-B., Jin, Q.-A. and Andfu, Y.-G. (2009): Biological characteristics of the spiralling whitefly, Aleurodicus disperses Russell (Homoptera: Aleyrodidae). Acta Entomol. Sinica 52, 281-289.

Hanafy, A. H., Awad, A. I. and Abo-Sheasha, M. (2001): Field evaluation of different compounds for attracting adults of peach fruit fly Bactrocera zonata (Saunders) and Mediterranean fruit fly, Ceratitus capitata (Wied.) in guava orchards. J. Agric. Sci. Mansoura University 26, 4537-4546.

Harris, E. J., Nakagawa, S. and Urago, T. (1971): Sticky traps for detection and survey of three tephritids. J. Econ. Entomol. 64, 62-65.

Hashem, A. G., Mohammed, S. M. A. and El-Wakkad, M. F. (2001): Diversity abundance of Mediterranean and fruit flies (Diptera: Tephritidae) in different horticulture orchards. Egyptian J. Appl. Sci. 16, 303-314.

Hasyim, A., Maryati, S. and Kogel, W. J. (2008): Population fluctuation of adult males of the fruit fly, Bactrocera tau walker (Diptera: Tephritidae) in passion fruit orchards in relation to abiotic factors and sanitation. Indonesian J. Agric. Sci. 9, 29-33.

Howlader, G. and Sharma, V. K. (2006): Circadian regulation of egg-laying behavior in fruit flies Drosophila melanogaster. J. Insect Physiol. 52, 779-785.

Jackson, J. K. and Resh, V. H. (1989): Distribution and abundance of adult aquatic insects in the forest adjacent to a Northern California stream. Environ. Entomol. 18, 278-283.

Jackson, J. K. and Resh, V. H. (1991): Periodicity in mate attraction and flight activity of three species of caddiflies (trichoptera). J. N. Am. Benthold. Soc. 10, 198-209.

Jones, O. T., Lisk, S. C., Longurst, G., Howse, P. E., Ramos, P. and Campos, M. (1983): Development of a monitoring trap for the olive fly Dacus oleae (Gmelin) (Diptera: Tephritidae) using a component of its pheromone as lure. Bull. Entomol. Res. 73, 97-106.

Katsoyannos, B. I., Kouloussis, N. A. and Carey, J. R. (1998): Seasonal and annual occurrence of Mediterranean fruit flies (Diptera: Tephritidae) on Chios island, Greece: Differences between two neighboring citrus orchards. Ann. Entomol. Soc. Am. 91, 43-51.

Kheder, B. S., Salleh, W., Awadi, N., Fezzani, M. and Jrad, F. (2011): Efficiency of different traps and baits used in mass trapping of Mediterranean fruit fly, Ceratitis capitata Wied. (Diptera: Tephritidae). IOBC/WPRS Bulletin 62, 215-220.

Lewis, T. and Taylor, L. R. (1964): The diurnal periodicity of flight by insects. Transactions of the Royal Entomol. Soc. of London 116, 393-469. 
Liquido, N. J., Shinoda, L. A. and Cunningham, R. T. (1991): Host plants of the Mediterranean fruit fly (Diptera: Tephritidae): An annotated world review. Miscellaneous Publications of the Entomol. Soc. of America $77,1-52$.

Maier, C. T. and Waldbauer, G. P. (1979): Dual mate-seeking strategies in male syrphid flies (Diptera: Syrphidae). Ann. Ent. Soc. Am. 72, 54-61.

Malavasi, A., Morgante, J. S. and Prokopy, R. J. (1983): Distribution and activities of Anastrepha fraterculus (Diptera: Tephritidae) flies on host and non-host trees. Annu. Entomol. Soc. Am. 76, 286-292.

Martínez-Ferrer, M. T., Navarro, C., Campos, J. M., Marzal, C. and Fibla, J. M. (2010): Seasonal and annual trends in field populations of Mediterranean fruit fly, Ceratitis capitata, in Mediterranean citrus groves: Comparison of two geographic areas in Eastern Spain. Span J. Agric. Res. 8, 757-765.

Mohamed, A. M. (2002): Seasonal abundance of peach fruit fly, Bacterocera zonata (Saunders) with relation to prevailing weather factor in Upper Egypt. Assuit J. Agric Sci, 33, 195-207.

Moustafa, S. A. and Ghanim, N. M. (2008): Some ammonium compounds as olfactory stimulants for Mediterranean fruit fly, Ceratitis capitata Wiedemann (Diptera: Tephritidae). J. Agric. Sci. Mansoura Univ., 33, 8965-8973.

Navarro-Llopis, V., Alearo, F., Dominguez, J., Sanchis, J. and Primo, J. (2008): Evaluation of traps and lures for mass trapping of Mediterranean fruit fly in citrus groves. J. Econ. Entomol. 101, 126-131.

Nielsen, T. R. (1966): Species of the genus Helophilus (Dip., syrphidae) found on Jaeren, Rogaland. Norsk Entomologyisk Tidsskrift, 13, 427-439.

Nripendra, L. and Hirak, C. H. (2010): The effect of meteorological factors on the population dynamics of melon fly, Bactrocera cucurbitae (Coq.) (Diptera: Tephritidae) in the foot hills of Himalaya. J. Appl. Sci. Environ. Manage. 14, 53-58.

Petersen, G., Hall, J. C. and Rosbash, M. (1988): The period gene of Drosophila carries species-specific behavioral instructions. EMBO J. 7, 3939-3947.

Pittendrigh, C. S. (1954): On temperature independence in the clock system controlling emergence time in Drosophila. Proc. Natl Acad. Sci., USA 40, 1018-1029.

Qureshi, Z. A., Siddiqui, Q. H. and Hussain, T. (1992): Field evaluation of various dispensers for methyl eugenol, an attractant of Dacus zonatus (Saund.) (Dipt., Tephritidae). J. Appl. Entomol. 113, 365-367.

Saafan, M. H. (2005): Field evaluation of some attractants for attracting the adults of Mediterranean fruit fly, Ceratitis capitata (Wiedemann) and peach fruit fly, Bactrocera zonata (Saunders) in citrus orchards. Egypt. J. Agric. Res., 83, 1141-1156.

Sakai, T. and Ishida, N. (2001): Circadian rhythms of female mating activity governed by clock genes in Drosophila. Proc. of the National Academy of Sciences of the United States of America 98, 9221-9225.

Sanjeev, R., Shankar, U., Bhagat, R. M. and Gupta, S. P. (2008): Population dynamics and succession of fruit fly on sub-tropical fruits under rained condition in Jammu Region. Indian J. Entomol. 70, 12-15.

Sarwar, M. (2006): Occurrence of insect pests on guava (Psidium guajava) tree. Pakistan J. Zoology, 38, 197-200.

Shehata, N. F., Younes, M. W. F. and Mahmoud, Y. A. (2008): Biological studies on the peach fruit fly, Bactrocera zonata (Saunders) in Egypt. J. Appl. Sci. Research, 4 1103-1106.

Sundar, P., Kumar, S., Chandra, S., Rajkumar, P. and Singh, D. K. (2015): Fruit flies, Bactrocera spp. relationship between trap captures and weather parameters. Annals of Biol. 31, 104-108.

SYSTAT (2011): More Statistics, More Graphs, Less Effort. Wass, John A. // Scientific Computing and Instrumentation; $21,11,31 \mathrm{p}$.

Thomas, M. C., Heppner, J. B., Woodruff, R. E., Weems, H. V., Steck, G. J. and Fasulo, T. R. (2008): Mediterranean fruit fly, Ceratitis capitata (Wiedemann) (Insecta: Diptera: Tephritidae). EENY-214 (IN371). Available from http:/ /creatures.ifas.ufl.edu. (accessed 15 December 2010).

Van Emden, H. F. and Service, M. W. (2004): Pest and Vector Control. First (ed.) Cambridge Univ. Press, Cambridge, pp. 1-362.

White, I. M. and Elson-Harris, M. M. (1992): Fruit Flies of Economic Significance: Their Identification and Bionomics. CAB International, Wallingford, UK $601 \mathrm{p}$.

Whittier, T. S., Kaneshiro, K. Y. and Prescott, L. D. (1992): Mating behaviour of Mediterranean fruit flies (Diptera: Tephritidae) in a natural environment. Annu. Entomol. Soc. America 85, 214-218. 
Willmer, P. G. (1982): Hygrothermal determinants of insect activity patterns: The Diptera of water-lily leaves. Ecol. Entomol. 7, 221-231.

Zimina, L. V. (1957): Stroeniye i funktsii kishechnika Syrphus (Diptera, Syrphidae), [Structure and function of the intestine of Syrphus (Diptera, Syrphidae)]. Zool. Zh 36, 1039-1043. (in Russian) 
